\title{
Determination of the Deterioration Characteristics of Facade Materials: A Case Study
}

\author{
Nil Kokulu \\ Antalya Bilim University, Faculty of Fine Arts and Architecture, Çıplaklı Mh. Akdeniz Blv. \\ Pk:07190 Döşemealt1, Antalya, nil.kokulu@antalya.edu.tr
}

\begin{abstract}
Deterioration of the facade materials of a building and its importance are topics that are not getting the attention that they deserve and need. If a material can't meet its accepted performance criterion during its service life then deterioration may occur on the surface, inside, under or at the structure of the material. Environmental, construction related, and human related agents collaborate with the mechanisms and make an effect which concerns the durability. Therefore, detecting the deteriorations of the materials play an important role for the maintenance planning. This study aims to detect the agents, mechanisms and effects of the deteriorations of a case building. A systematic approach was developed by making literature review. Hostile environmental analysis and building facade inspection have been made by the visual observations on a specific day. Deteriorations occurred at granite, wood composite, aluminum, glass and ceramic materials have been discussed.
\end{abstract}

Keywords: Environmental Deterioration, Facade Inspection, Agents, Mechanisms, Durability.

\section{Introduction}

Building components are expected to maintain their required performance levels over their service life. In order to succeed in this process, identifying the environment and the future cause of the deteriorations are a precondition. During the literature reviews, it is seen that facade materials such as granite, wood composite, aluminium, glass and ceramic are exposed to deteriorations as time progresses.

According to Grelk et al. (2007), bowed granite cladding is a problem caused by the temperature differences and the moisture. Also, Marie (2013), in her article, states that natural stone facades perform differently over time and the colour of the facade may change according to cracking, dirt, corrosion, carbonation and biological colonization. This change causes visual aesthetic problems and the problems may differ according to person's characteristics.

Morrel et al. (2010), state that as a biological agent, white rot fungi and brown rot fungi can easily deteriorate wood in wood plastic composites (WPC) and may cause loss of weight depending on the climate. The most important factor was determined as moisture for fungal decay. They also argue that WPC's bending properties change when exposed to fungi. The authors go on to say that physical agents are also important when deterioration of WPC's is the subject. Although the damage seems like it is on the surface, chemical discoloration occurs beneath the surface and it is very difficult to remove. Also, UV degradation changes the characteristics such as colour, surface composition and mechanical changes of WPC's.

According to Honfi et al. (2014), in their article about the glass structure failures, they described two kinds of exposures which are faults and errors. Faults are the physical reason for the failures such as excessive loading, surface damage and moisture, while errors are the logical reason of the exposures such as modelling and calculation errors, poor manufacturing and detailing errors. 
Corrosion is most common in metals and observed to some extent in ceramics. Khanam et al. (2015), state that corrosion on aluminium has seen because of the saline environment. They state that chloride ions attack to aluminium film and made pits on the top. This causes structural failure of the material.

Besides the obvious problems of breakage, ceramics deteriorate during their service life according to temperature, external loads, vibrations and environment. They may contain soluble salts which can crystallize at or near the surface and destroy the material. Also, unstable glazes of the ceramics may cause crumbs on the surface (Museum Management Programme, 2018).

In this study, the deteriorations formed in granite, wood composite, ceramic, aluminum and glass and their causes have been explained systematically. Agents, mechanisms and effects of the deteriorations were identified. Results and expected damage are explained at the end.

\section{The Case Study}

\subsection{Preparing the Data Analysis}

In this section, specific data, information and analysis of the front facade of the building are intended to provide a proper method for conducting the deteriorations. The first part of this section provides a draft of the proposed systematic approach to study that reflects on an individual understanding and perception of the research process. The second part consists the inspections of the hostile environment and the facade of the building. For the hostile

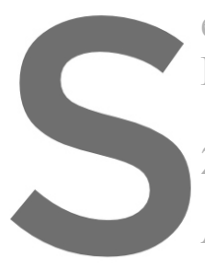
environmental analys is, For the facade of the buin 2.2 Systematic Appro A systematic approach is a
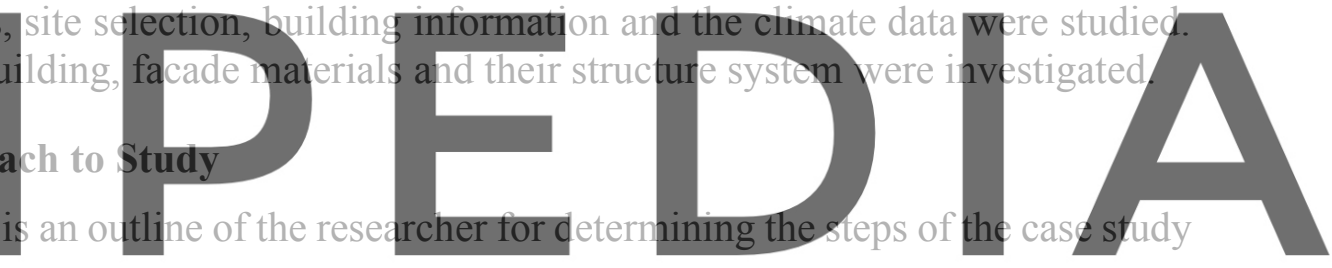

(Figure 1).

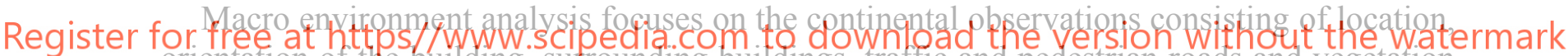
orientation of the building, surrounding buildings, traftic and pedestrian roads and vegetation at the site. Meso environment analysis consist of climate type, dominant wind direction, temperature, precipitation, air content, pollution and soluble salts which influence the building. Micro environment analysis consist of age, height, architectural form, function, facade materials, material types, their characteristics and material structure system.

Data collected after the macro, meso and micro analysis and was used as a component while making the visual observations. Visual observations consist of the sunny and rainy-day conditions of the east facade. According to this conditions, agents of the deterioration have been analyzed by taking the feedback from the literature review. According to Kuş (2018), agents in the built environment very rarely act alone but neither work together. The effect of the agent occurs when a mechanism reveals its appearance.

Performance deteriorates at a rate depending on the environment, the design of the building, building materials, maintenance and usage (Song and Lim, 2016). In this case, since the building is at a very young age, it is not possible to visually observe the deteriorations but estimate them with the help of site analysis and visual observations.

Although all the visual information and the literature review provided, it is not possible to be certain about the future deteriorations. 


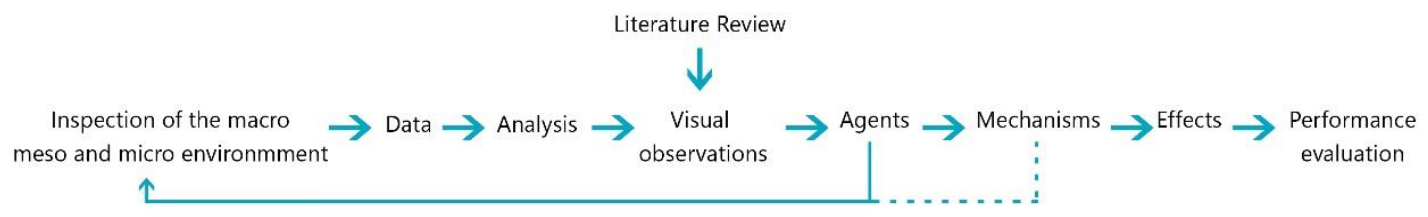

Figure 1. A systematic approach.

\subsection{Macro Environment}

The building is located on the intersected corner of Portakal Çiçeği street and 1460 street in Antalya, Turkey. It is a seven storey-high residential building on the right with a distance of 8.40 meters, ten storey-high residential building on the back with a distance of 14 meters and front with a distance of 40 meters and two storey-car parking on the southwest with a distance of 21.5 meters. The main entrance faces to east (Figure 2). This facade always takes the sun directly without having any shading areas. The temperature and the light play a crucial role on materials. 1460 street and Portakal Çiçeği street have intense traffic. This causes air pollution which may create deterioration. The distance from the sea is $1 \mathrm{~km}$ and the height of the building from the sea is $22.5 \mathrm{~m}$. The pedestrian roads and the vegetation around the building can be seen in Figure 3. There is an open area in front of the main facade. There are also car parking areas on the east and the west facade.
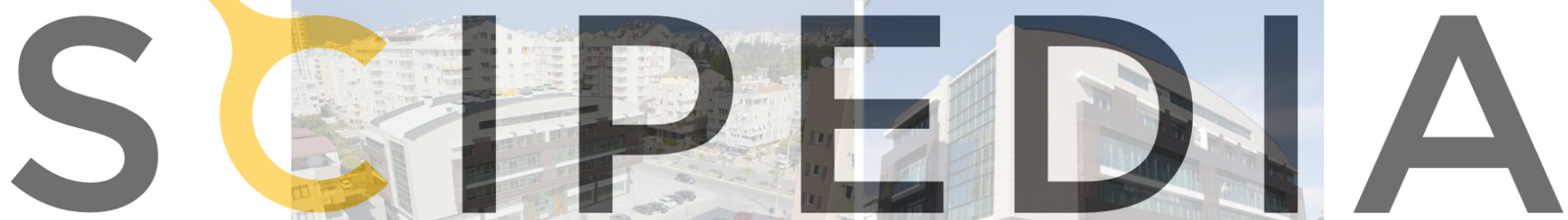

Register for free at https//www.scipedia.com to download the version without the watermark

Figure 2. East facade of the building.

\subsection{Meso Environment}

Antalya has a hot humid climate with rainy winters. The dominant wind direction is from northeast to southwest (Figure 3). The temperature changes $10^{\circ} \mathrm{C}$ to $35^{\circ} \mathrm{C}$ through the year. October, November and December are the months that take most of the rainfall (Holidayweather, 2018).

The air contaminates soluble salts because of the distance within the sea. This may cause material deteriorations by collaborating with the mechanism. According to SIMM Project, Sulphur dioxide and particulate matter has been diagnosed in the air (Sürekli Eğitim Merkezi, 2019). Sulfur dioxide and its acid derivations are known to cause considerable damage to materials. The east and north facade is open whereas the south and west facade are in the shade caused by surrounding buildings. There isn't so many people around the building except the Wednesdays because of the local bazaar. The building welcomes the animals. 


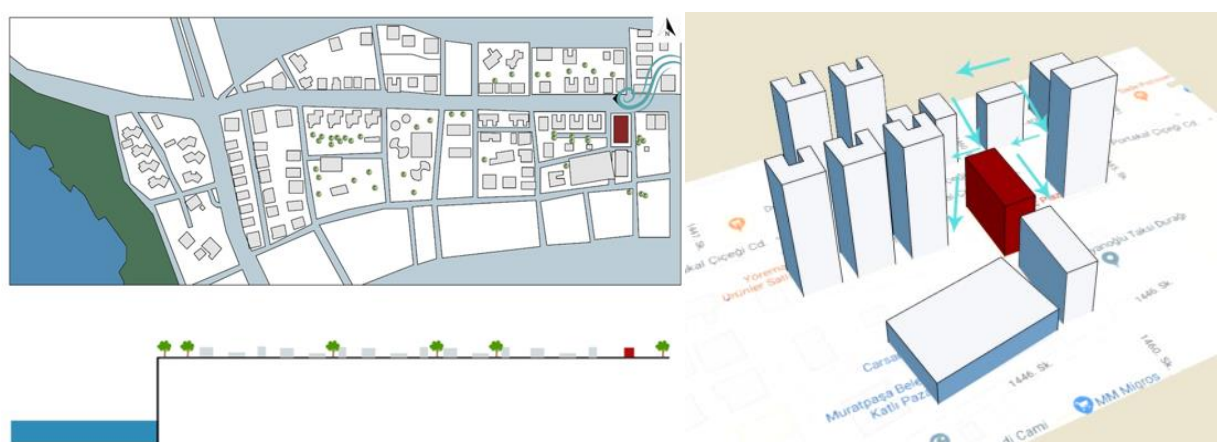

Figure 3. The site plan, the section of the site (on the left) and dominant wind direction and the movement around the building (on the right).

\subsection{Micro Environment}

The six-storey office building is three years old. It has a rectangular form with the dimensions of 42.50 meters to 18.95 meters. The height of the building is 18.60 meters. The facade materials of the modern designed building are ceramic, aluminum, glass, granite and wood composite (Figure 4). The properties of the materials can be seen on Table 1.
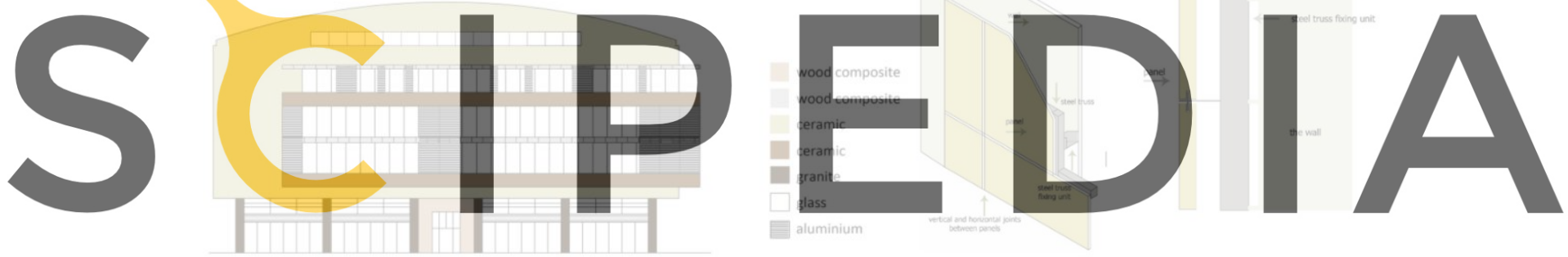

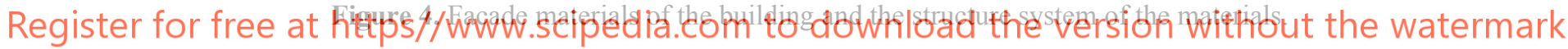

Table 1. Properties of the facade materials

\begin{tabular}{lll}
\hline Materials & Color & Surface finish \\
\hline Ceramic & beige & unglazed \\
\hline Ceramic & brown & unglazed \\
\hline Granite & black & polished \\
\hline Aluminium & white & polished \\
\hline Wood composite & white & flat \\
\hline Wood composite & light brown & flat \\
\hline Glass & blue & flat
\end{tabular}

Steel truss metal panel curtain wall system has been used for the facade system. A cross or vertical steel truss is installed on the structure first. Then, a panel is fixed to the steel truss. Finally, the vertical and horizontal joints between the panels are filled with back-up materials and then finished with sealant. No anchorage system and no joints can be seen from the external (Figure 4) (Song and Lim, 2016). The corner adjoining parts of the granites are unpolished. This part may take water and air to the inside and different types of deteriorations may occur. 


\section{Analysis}

\subsection{Visual Observation Information}

For the case study, visual observations are made. The observations took two hours from 12.00 to 14.00. The materials on the east facade have been examined according to their instant conditions in a sunny day and in a rainy day (Table 2 ). Also, future deterioration problems are discussed.

Table 2. Visual observation conditions.

\begin{tabular}{lcc}
\hline & Sunny day conditions & Rainy day conditions \\
\hline Observation day & 10.11 .2018 & 17.11 .2018 \\
\hline Climate type & Winter & Winter \\
\hline Temperature & $17^{\circ} \mathrm{C}$ & $14^{\circ} \mathrm{C}$ \\
\hline Humidty & $43 \%$ & $86 \%$ \\
\hline Wind direction & $\mathrm{NE} \mathrm{to} \mathrm{SW}$ & $\mathrm{NW}$ to SE \\
Wind speed & $3 \mathrm{~km} / \mathrm{h}$ & $21 \mathrm{~km} / \mathrm{h}$ \\
\hline Rain ration & $0 \%$ & $70 \%$ \\
\hline
\end{tabular}

According to sunny-day and rainy-day conditions shading areas of the building have been examined. The facade of the building takes most of the sun except upper part of the facade of the ground floor in a sunny day, while it is totally in shade in a rainy day.
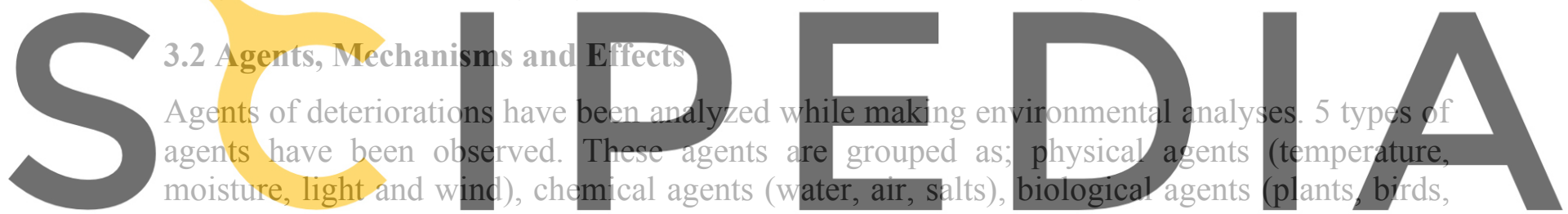
mold), design decisions, vandalism.

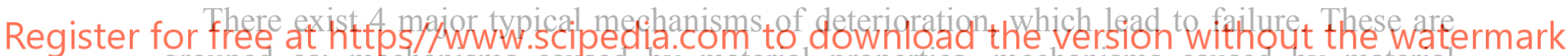
grouped as; mechanisms caused by material properties, mechanisms caused by material structure properties, environmental mechanisms, construction related mechanisms.

A review of the causes of failure identified twelve of the most frequent sources of deterioration in facade materials are; dirt and dust accumulation, spalling, biological colonization, staining, corrosion, efflorescence, gypsum crust, cracks and breakage, discoloration, UV degradation, chipping, scratches. Agents, mechanisms and effects of the deterioration for each facade material can be seen in Table 3.

\section{Results and Discussions}

In this study, visual observations have been made to determine the future deteriorations. Since the building is only three years old, only the dirt deposition and the discoloration on the surface of the granites and discoloration on the WPC's caused by the rain have been observed. Expected deteriorations of the materials are discussed below.

Dirt and dust deposition occur on the cracks and on the surfaces of the panel with the help of the wind. High traffic areas cause great accumulation of dirt (Museum Management Program, 2018). The east facade is located on one of the most intense traffic areas. Dirt and dust deposition would be seen on the granite columns in the future. Wind can bring salts in the 
air to the panel surface which can cause spalling (Museum Management Program, 2018). Spalling couldn't be seen on the front side of the columns. But it is seen on the north side of the columns. The reason is, the east side takes the sun more than the north side and can easily dry whereas the north side is always on shade. Biological agents such as bacteria, algae, fungi, and moss grow on stone surfaces and cracks with the help of humidity (Museum Management Program, 2018). The lower side of the columns can easily deteriorate because they are exposed to water more than the higher parts. Color changes on the panel surfaces may be caused by the design decisions. The sun plays an important role for this type of deterioration. This may also effect visual aesthetics (Mauko et al., 2006).

Bowing and expansion due to temperature changes (Grelk et al., 2007) may occur on the front side of the columns with the help of the temperature. Staining from water absorbtion or vapour condensation may occur on granite (ICOMOS, 2019). The corners of the granite are capable of water intake. Corrosion occurs when the chemical reactions happen (Shaw and Kelly, 2006). The corners of the granite have started to corrode and may cause structural problems in the future. Ceramics may contain soluble salts that can crystallize at or near the surface and destroy the panel (Museum Management Program, 2018). The adjoining parts of the ceramics are capable of salt intake. So, the efflorescence is possible.

Because of the location of the facade, air pollution may cause wet deposition where there is no rain-wash. This may cause gypsum crust (Agnes et al. 2012). Observations after the rain showed that, some part of the ceramics dry longer than the other parts. Condensation can lead

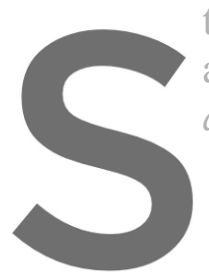
to mold growth, noxicur

\section{and Paschoal, 2002)}

al. 2012). Cracking occt
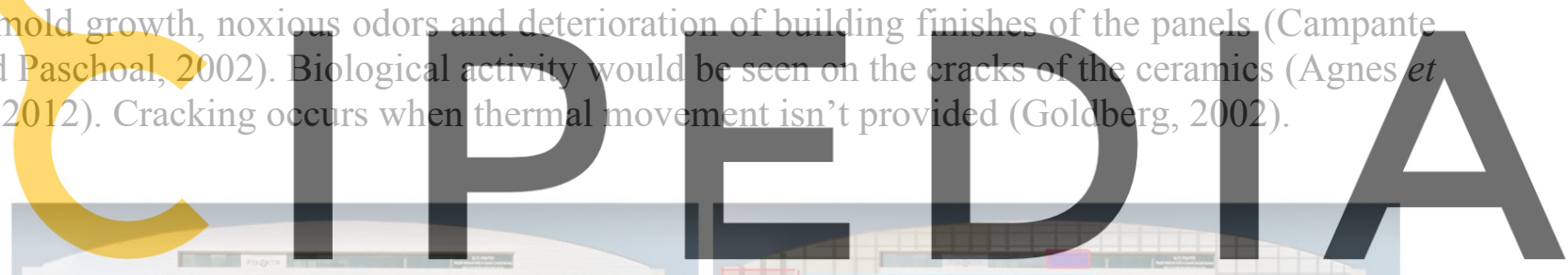

Register for
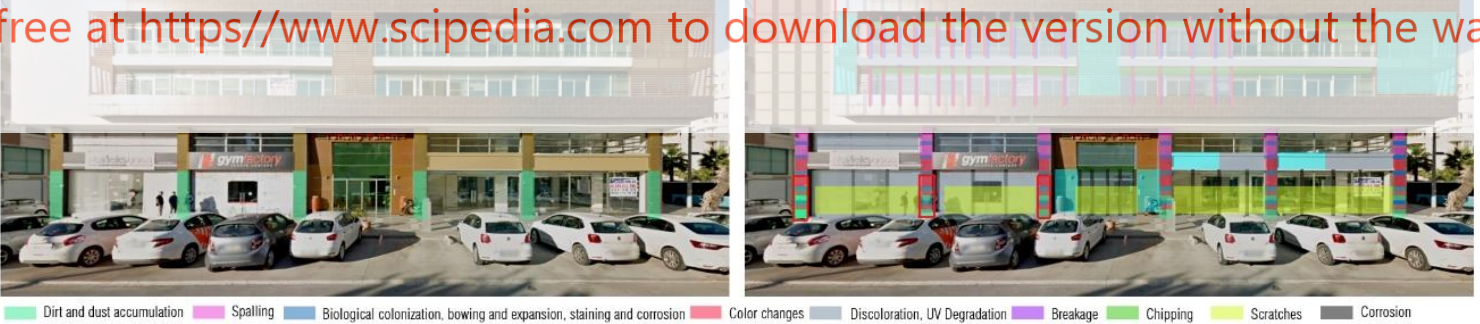

Dirt and dust accumulation Spalling
Color changes

Figure 5. Facade of the building (on the left), facade of the building in 30 years (on the right).

The panels would be affected by the temperature. It is clearly seen that no expansion joint was used, either vertical or horizontal. This may cause cracks and/or breakage even falling of the panels. Corrosion may occur on the metal structural supports and anchors of ceramic tiles (Campante and Paschoal, 2002). The panel joints may easily take water and air inside of the structure. Color changes create visually unproper aesthetic that can be seen on the ceramic tiles (Song and Lim, 2016). The reason of this can be dirt deposition which comes with the wind. Biological agents may use wood as a food source or for living with the help of water intake from the cracks or joints. This may cause weight loss of the panel (Morrell et al., 2010). The WPC's on the east facade can easily take water from the rain. It is clearly seen that air pollution 
came with the rain and created a color change at the surface. Because of the absorption characteristics of the WPC's moisture may cause damage of the material especially on the shading areas (Morrell et al., 2010). The lower parts of the wood composite look better than the upper parts. It is probable that the upper parts would have a mechanical degredation in the future. Especially in the summer, the sun plays an important role. Wood absobs the UV lights. This causes loss of surface quality and change in the mechanical properties. UV degradation would be seen at the WPC's especially on the unshaded areas in the future.

Table 3. Agents, mechanisms and effects of the deteriorations.

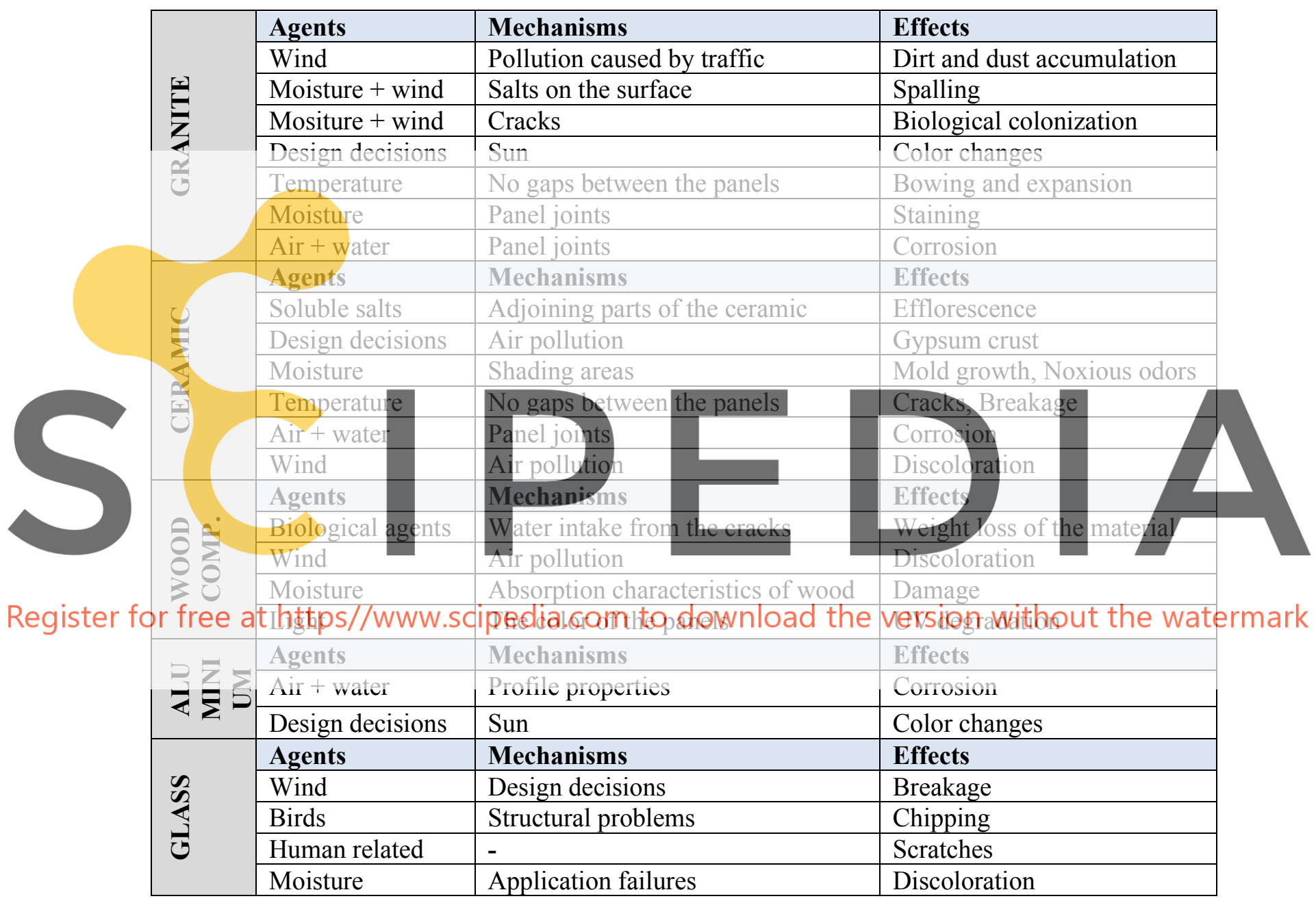

Because of the design decisions, wind cause breakage of the glass panels which are not in a proper location of the facade (Honfi et al., 2014). This may occur on the northeast side of the building because of the dominant wind direction. Birds cause chipping on the edges of the panels arised from the structural problems (Honfi et al., 2014) This may occur on the upper parts of the façade. Vandalism may occur on the lower parts of the building on glass. Cleaning the panels with inappropriate materials may lead to deterioration. Moisture may ruin the mechanical and physical properties of stone and this causes discoloration. Since most of the building gets rain-washed, the glass panels can easily lose their visual aesthetics. 
The method presented in this paper was developed as a tool for the prediction of the service life of building components. Deteriorations have been anaylzed by a systematic approach using environmental analysis, visual observations and literature review. It is clearly seen that, deteriorations on the facade of the building will occur in the future (Figure 5).

\section{Acknowledgement}

This research has been supported by a PhD class called Performance of Building Elements Under Environmental Effects given by Professor Doctor Hülya Kuş at İstanbul Technical University. I thank her for comments that greatly improved the study.

\section{ORCID}

Nil Kokulu: https://orcid.org/0000-0002-7057-7601

\section{References}

Agnes, B., Toth, M., Bajnoczi, B. and Szabo, C. (2012). Deterioration of Building Ceramics by Environmental Factors, A case study on Zsolnay Ceramics from the Museum of Applied Arts (Budapest), Geosciences and Engineering, 1(2), 7-14.

Campante, E. and Paschoal, J. (2002). Durability of Facades with Ceramic Coverings, IX International Conference on Durability of Building Materials and Components, Brisbane, Australia, 60, 1-10.

Goldberg, R.P. (1994). The Effects and Control of Moisture in Ceramic Tile Facades, III World Congress on Ceramic Tile Quality, Castellon, Spain, 231-247.

Grelk, B., Christiansen, C., Schouenborg, B., Malaga K., Hoigard, K., Scheffler, M. and Dean, S.W. (2007). Durability of Marble Cladding-A Comprehensive Literature Review, Journal of ASTM International, 4(4).

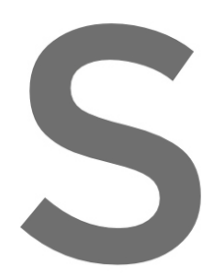
doi: $10.1520 / J A I 10085$

Holiday-weather (2018, Decer https://www.holiday-w

Honfi, D., Reith, A., Vigh, glass structures, Louter, Bos, Belis \& Lebet (Eds Conference, London, Bngland, Taylor \& Francis Group

ICOMOS (2019, January). Illustrated Glossary on Stone Deterioration Patterns, Monuments and Sites,

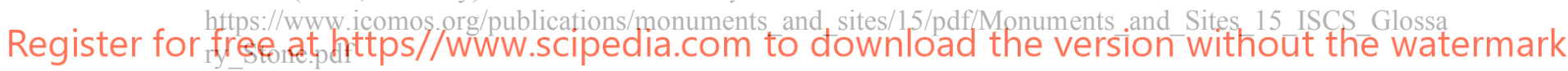

Khanam, Z., Singh V. and Zaidi, M.G.H. (2015). Effect of Environment on Corrosion Behaviour of Aluminium, International Journal on Environmental Sciences, 6(2), 281-286.

Kuş, H. (2018). YAB 615 E Performance of Building Elements under Environmental Effects: Agents, Mechanisms and Effects, $\mathrm{PhD}$ class, fall lecture notes.

Marie, I. (2013). Perception Of Darkening of Stone Facades and The Need For Cleaning, International Journal of Sustainable Built Environment, 2(1), 65-72. doi: https://doi.org/10.1016/j.jisbe.2013.09.001.

Mauko, A., Mirtic, B., Mladenovic, A. and Grelk, B. (2006). Deterioration of the Granodiorite Facade, Materials and Geoenvironment, 53(1), 23-37.

Morrell, J.J., Stark, N.M., Pendleton, D.E. and McDonald, A.G. (2010). Durability of Wood-Plastic Composites, 10th International Conference on Wood \& Biofiber Plastic Composites, 16(3), 7-10.

Museum Management Program (2018, December), Museum Handbook Part 1, Appendix P: Curatorial Care of Ceramic, Glass, and Stone Objects. https://www.nps.gov/museum/publications/MHI/AppendP.pdf

Shaw, B.A. and Kelly, R.G. (2006). What is Corrosion?, The Electrochemical Society Interface. Retrieved January 5, 2019 from https://www.electrochem.org/dl/interface/spr/spr06/spr06_p24-26.pdf

Song, S.Y. and Lim, J.H. (2016). Evaluation of Alternatives for Reducing Thermal Bridges in Metal Panel Curtain Wall Systems, Energy and Buildings, 127(1), 138-158. doi: https://doi.org/10.1016/j.enbuild.2016.05.078

Sürekli İzleme Merkezi (January 2019). http://www.havaizleme.gov.tr/Services/AirQuality. 